\title{
Discussion on Application of Information Technology in Internship in Hotel and Tourism Management
}

\author{
Zhihui Li \\ Pingdingshan Institute of Education, Pingdingshan, 467000, China
}

Keywords: Information technology. Hostel and hotel. Internship in management. Application

\begin{abstract}
Along with the continuous development of current social economy, the science and technology level have been gradually improved, the information technology has drawn more and more attention of people, and it is applied widely to all areas with significant result. As for students from higher vocational colleges and Hospitality Management, with the great influence on service industry development, these future social talents shall not only conduct professional basic services, room services and catering services, great information training program shall also be required in the internship in hotel and tourism management. Therefore, the quality of internship could be improved and good foundation would be constructed. A brief discussion shall be conducted in this article targeted on application of information technology in internship in hotel and tourism management, which is for reference only.
\end{abstract}

\section{Introduction}

With step-down of existing new curriculum reform, the teaching pattern and methods are in large changes. To higher vocational colleges, the major in hotel and tourism management has provided huge number of serviced talents. Presently, along with rapid technology development, during the internship in tourism and stage management, with the help of information technology (IT), the teaching results could be improved and students could adapt to society faster. A brief discussion on application of IT in internship in hotel and tourism management and relevant contents would be conducted as following, and it is for references only.

\section{Significant Meanings of Internship}

Practical training is an important part of overall teaching program of hotel and tourism management (H\&TM), and it is also an important component of students' future career. The internship could help students to combine theories and practical application together closely. For a long time, as to teaching pattern existed in higher vocational colleges, teachers would like to explain theories as guidance to students, hence, with excellent results in colleges, students may get pain in all around after entering the society with feeling of loss, and then they may lose the passion and motivation of works, bad effects may be made onto these students. However, the internship could help out. By cooperating with enterprises, practice platform would be provided to help students clearly and further understand the theories they learnt, and transfer the knowledge to practical applications. Through the way of making students study the content of social position while they are still in colleges, they can suit to the development of society better, and construct a solid foundation for their future career.

\section{Deficiencies in Previous Internships}

As for the modern higher education, with long time development, the teaching pattern has been mutual and perfection gradually. However, the teachers and staff are paid too much attention on explaining theories and ignoring the training of techniques. Therefore, a separation condition has been shown between theoretical study and practical application. What's more, the function of modern IT application in teaching and management program has been omitted. Many teachers and students 
do not realize the importance of IT application in internship, and even do not have correct understanding of internship activities. During the training period, by less connection with IT, the quality and efficiency of teaching are low.

During the teaching program, some of the course contents shall be combined with a large number of practical training. Yet to several teachers applied textbook contents mechanically to classroom instruction simply, the internship has been overlook. In spite of spending a lot of money in lab construction by higher vocational colleges recently, efficiency in application is relatively low: when training activities is going to be conducted, the teacher would inform lab management personnel the content of the practice, and prepare the relevant equipments and materials in advance, and then the students can simply finish practice in lab under relevant instruction. Problems are hard to be spotted during internship by the above way, and they could not learn more throughout the practice. The efficiency of internship is imprisonment. Additionally, internship activities are always focusing on common programs, with less connection of IT and low practical effect.

When students joined in school-enterprise cooperation process, the teachers, staff and mangers shall develop in-depth discussions on reposition of correct internship management and the way of getting credit for students, and also on how to create a series of scientific, reasonable and high efficient management standards. During the internship, lots of students have taken up positions as waiters, so they would have less connection with IT training program, and there is no tracing supervision for students. Furthermore, with location of internship scattered in a wide range and less advisors on duty, many students are under the situation without supervision, so the function of internship cannot be worked out. Hence, practice shall be combined with theories, and various teaching objectives shall be formulated with different majors of students, so that the effect of internship could be fully made to construct a solid foundation for students.

\section{Method of Applying IT to Internship in Hotel and Tourism Management}

As for higher vocational colleges, the students who are major in hotel and tourism management could not only play a role of manager or operator in tourism, hotel or catering enterprises, but they also could act as junior staff - even for mangers, they also need to start from juniors. Therefore, to the above students, they have to be on top of relevant professional knowledge, and the have to be equipped with basic practical ability. Hence, internship becomes very important. To teachers and staff, before conducting the training program, they have to integrate IT to create precise and scientific teaching plan, develop internship by stages and modules, and enhance the remote monitoring, and promote the internship quality to help students improve their self-development.

\section{Introduction to Professional Practice}

Teachers shall prepare a detailed internship planning to meet the features and requirements of hotel and tourism before internship program conducted. They have to start from source, develop in proper sequence, and guide in classification. The first lesson for students is to greet guests respectfully, including departure and landing process for clients, check in and check out the hotels, solutions for unique requirements etc. Relevant theories includes “Tourism Science”, "Marketing”, "Psychology”, "Etiquette Study”, “Management”, etc. In order to explain relevant contents with high efficiency and quality, students are suggested to be positioned in the hotel lobby, show room for internship, including enquiries, reception, indicator and control system at front desk. Furthermore, the "Lobby and Housekeeping Management" involved in internship shall be conducted as on-site simulation to realize a flexible and vivid effect, and then the teaching quality can be improved. All the contents mentioned above are the basic knowledge that students with major in hotel and tourism management have to master. By internship program, students shall master reception and relevant information more precisely to make a solid foundation for their future growth.

\section{Guestroom Technology Practice}

Guestroom technology is another basic professional ability that the students in major of hotel and tourism management in higher vocational colleges have to hold. It includes practice of making bed in the form of Chinese or western; practice of standard room and suite, etc. Relevant courses are: "Hotel Etiquette Service”, “Guestroom Management”, “Equipment Management”, etc. During the class lectures, students shall be instructed to remember related knowledge firmly. For example, when 
teachers gave lectures on "Making Bed in forms of Chinese or Western", students shall be prepared ahead with related materials including pillow, pillowcase, sheet, quilt cover, beds, etc. to practice. Subsequent internship, practice of standard room and suit, can only be open up until students could master basic making bed skills.

The conventional tools would be used in standard room are: bedside lamp, night table, dressing table, writing desk, end table, dust extractor, etc. Students shall be familiar with operation procedures and standards for above equipments. By internship, student would grasp modern hotel housekeeping services clarity and suit the development of society better. Moreover, to increase the quality of internship, teachers shall display some pictures and videos from western well-known hotels to develop study in comparison.

\section{Catering Service Technology Practice}

During the catering service technology practice, the training of Chinese and western food culture shall be highlight by teachers, various eating patterns with different regions and countries shall be mastered by students, and the at home feeling shall be provided to customers. Therefore, catering technology practice is very important for students from hotel and tourism management of higher vocational colleges. During the internship, teachers shall create a good teaching atmosphere for students, to make them personally on the scene, and then the operant level would be improved. All the knowledge points involved in Chinese and western food training includes "Chinese and Western Food Culture”, “Catering Management and Services”, etc. After the practice conducted, students' theoretical knowledge ability shall be enhanced and the capability of intermediate waiter qualification and senior water qualification shall be equipped as well. Teachers could make students practice through on-site simulation or IT method. For instance, because of distant tea culture history, unique tea ceremonies are formulated in different places, therefore, when giving lectures on tea services and relevant knowledge, IT method shall be introduced by teachers to instruct students in mastering different kinds of tea ceremonies, to enrich the knowledge reserves and improve the teaching quality, so when customers tastes their own hometown tea culture, they would feel good. Another example: great spirits culture differences could be found between the East and the West, it is a representative of a nation's character and temperament. Hence, to students from hotel and tourism management of higher vocational colleges, relevant skills of spirits culture shall be mastered. By internship, not only the basic skill of making tea and blending wine could be mastered, students could also look-into all civilization around the world, which would lay the root for their future growth.

In use of the practice of tea and spirits, students could memorize relevant knowledge clearly, and related skill training would enhance their art conservation and professional ability. To cut cost input, teachers no need to prepare actual materials for students to practice, with the help of IT, videos of some regions and countries could be displayed to increase students' knowledge and draw their attention, and then the teaching quality could be improved.

\section{Students' Ability of IT Application Improvement}

With constantly scientific and technological level enhancement, IT has been applied to various fields, and played an important role. Similarly, computer technology has been applied in hotel and tourism enterprises widely. Colleges could build a local area network (LAN) to make hotel information simulation practice to improve the IT level of students. The practice includes: reservation practice, front desk practice, equipment practice, guest room practice, accounting practice, etc. With overall simulation practice, the IT level of students could be enhanced. Additionally, during the course of “Accounting”, "Electronic Commerce", etc, a network platform could be provided for students to train their management ability in online hotel management. What's more, teachers shall lead students to master the creation and management of computers, and make them equipped with IT to keep closely pace of age.

\section{Remote-monitoring of Internship Enhancement}

In facing numbers of attaching enterprises that widely spread, and short of advisors in which students free from supervision, and to ensure the quality of internship, students shall cooperate with attached enterprises, create online communication and exchanges platform with IT to implement remote-monitoring and real-time supervision over students, and then the effect of internship could be 
reflected. Through the internet, students can ask questions when they come across with problems, then teachers would provide correct answers to help them. In this way, not only the problem of teachers shortage could be solved, but the high efficiency internship quality can be guaranteed, win-win objective could be achieved, and the solid foundation could be constructed for students.

\section{Conclusion}

In a word, as the saying goes, it takes ten years to grow trees, but a hundred to cultivate people. Education is a fundamental task for the coming generation. with constantly improvement of scientific technology, patterns and methods of teaching have changed a lot. IT internship work shall be developed with great effort to improve the comprehensive qualities and professional techniques of students from hotel and tourism management of higher vocational colleges, and then help the students to combine theories with practice to suit the development of age to better adapt to future position, so that the students could improve their own growth.

\section{References}

[1] Feng Jiushan, Liu Hongfang, Fang Binyu, Yang Yanjia, Yang Yu: Investigation on New pattern of Food Safety Supervision and Management in Restaurant Chain; Chinese Journal of Public Health management, 2001 (04).

[2] Zhang Ruihai: Exploratory Analysis of Sustainable Development of Bay Coastal Tourism in North Guangxi, Journal of Guangxi University for Nationalities, 2011 (04).

[3] Huang Shengxia, Wu Guofu: Study on Evaluation of Ecotourism Resources and Benefit Compensation on the Basis of Chess Play, Anhui Agricultural Sciences, 2011 (22).

[4] Ran Jingcheng: Eco-tourism Development and Conservation of Natural Resources for Maolan Reserve; The Transformation of Economic Development Patterns and Independent Innovation - the Twelfth Annual Meeting of China Association for Science and Technology (Vol. 1) , 2010.

[5] Ping Xiucheng, Wang Renbin: Proactively Develop Dadong Mountain Eco-tourism Resources, Create Eco-tourism New Business Card in Effort, Jiangsu Business journal, 2009

[6] Li HUI: Major Construction and First Exploration in Reform of Academic Tourism Management -Taking Tourism Management in Changchun Normal University as Example, Journal of Changchun Education Institute, 2011 (03).

[7] Lin Zhixing, Li Junlong: Discussions on Healthy Sustainable Development of Tourism -Taking Taining, Fujian as Example, Journal of Chifeng University for Natural Science, 2010 (04).

[8] Wang Shuzhen: Study on Reform of Professional Ethics Course System under Circumstances of Integration of Work and Study Mode, Heilongjiang Education (Higher Education Research \& Appraisal), 2009 (06). 